TODESCHINI, Guilherme dos Santos. Redução do Parlamento brasileiro com inspiração no modelo dos Estados Unidos: a inconsistência objetiva do argumento em trânsito no Congresso Nacional brasileiro. Revista Eletrônica Direito e Política, Programa de Pós-Graduação Stricto Sensu em Ciência Jurídica da UNIVALI, Itajaí, v.14, n.2, $2^{\circ}$ quadrimestre de 2019. Disponível em: www.univali.br/direitoepolitica - ISSN 1980-7791

\title{
REDUÇÃO DO PARLAMENTO BRASILEIRO COM INSPIRAÇÃO NO MODELO DOS ESTADOS UNIDOS: A INCONSISTÊNCIA OBJETIVA DO ARGUMENTO EM TRÂNSITO NO CONGRESSO NACIONAL BRASILEIRO
}

REDUCTION OF BRAZILIAN PARLIAMENT WITH INSPIRATION IN THE US MODEL: THE OBJECTIVE INCONSISTENCE OF THE TRANSIT ARGUMENT IN THE BRAZILIAN NATIONAL CONGRESS

\author{
Guilherme dos Santos Todeschini ${ }^{1}$
}

\section{RESUMO}

O presente artigo propõe-se a examinar, de modo objetivo, a veracidade do argumento de que o Poder Legislativo nos Estados Unidos é mais enxuto do que no Brasil. Esse argumento embasa algumas proposições legislativas com trâmite no Congresso Nacional brasileiro que visam a redução do número de parlamentares. O exame proposto deu-se pelo método quantitativo, via cruzamento e comparação de dados sobre contingentes populacionais e de parlamentares em ambos os países. Pôde-se concluir, pelo estudo, que, considerando-se os planos nacional e estadual, o Poder Legislativo nos Estados Unidos não é mais enxuto do que no Brasil, mas sim o contrário.

PALAVRAS-CHAVE: Representação Parlamentar; População; Poder Legislativo; Democracia Representativa; Comparação.

\begin{abstract}
The purpose of this article is to examine, in an objective way, the veracity of the argument that the Legislative Power in the United States is leaner than in Brazil. This argument bases some legislative proposals with process in the Brazilian National Congress that aim at the reduction of the number of parliamentarians. The proposed examination was done using the quantitative method, through crossing and comparing data on population and parliamentary contingents in both countries. It could be concluded from the study that, considering the national and state plans, the Legislative Power in the United States is not leaner than in Brazil, but rather the opposite.
\end{abstract}

KEYWORDS: Parliamentary Representation; Population; legislature; Representative Democracy; Comparison.

1 Especializando em Direito Constitucional (Complexo de Ensino Renato Saraiva/Sociedade de Ensino Superior Estácio de Sá). Advogado Público no Instituto Municipal de Estratégia da Saúde da Família (IMESF). Porto Alegre/RS, Brasil. E-mail: <gui.todesca@gmail.com>. 
TODESCHINI, Guilherme dos Santos. Redução do Parlamento brasileiro com inspiração no modelo dos Estados Unidos: a inconsistência objetiva do argumento em trânsito no Congresso Nacional brasileiro. Revista Eletrônica Direito e Política, Programa de Pós-Graduação Stricto Sensu em Ciência Jurídica da UNIVALI, Itajaí, v.14, n.2, $2^{\circ}$ quadrimestre de 2019. Disponível em: www.univali.br/direitoepolitica - ISSN 1980-7791

\section{INTRODUÇÃO}

Observa-se, de algumas proposições legislativas apresentadas no Congresso Nacional brasileiro, que foram apresentadas propostas de redução do número de membros do Poder Legislativo brasileiro. Algumas dessas propostas apresentam como modelo de inspiração, para justificar-se, a realidade representativa parlamentar dos Estados Unidos (que seria mais enxuta que a brasileira).

No estudo que embasou o presente escrito, buscou-se desvendar, via metodologia de caráter objetivo, se o Poder Legislativo dos Estados Unidos é de fato mais enxuto que o brasileiro - e, consecutivamente, se a realidade de representação parlamentar nos Estados Unidos pode ser utilizado como argumento justificador da redução de membros no Poder Legislativo brasileiro.

Utilizou-se, como forma de abordagem do tema, o método hipotético-dedutivo (buscando-se aferir se a hipótese do argumento que embasa as propostas legislativas era confirmada ou negada pelos dados objetivos coletados). Como forma procedimental de análise, utilizou-se os métodos estatístico (para aferir-se as proporções da representação parlamentar em relação à população no Brasil e nos Estados Unidos) e comparativo (via confronto dos dados estatísticos da representação parlamentar de cada país) ${ }^{2}$

A conclusão a que se chegou, após a análise dos dados, é a de que o argumento em utilizado no Congresso Nacional brasileiro não se justifica devido ao fato de número de membros do Poder Legislativo nos Estados Unidos é proporcionalmente (em relação à população representada) maior do que no Brasil.

\section{ARGUMENTO DAS PROPOSTAS NO CONGRESSO NACIONAL BRASILEIRO}

A questão relativa ao tamanho dos parlamentos dialoga com sua função representativa. É no balanço dessa relação que emerge o que Bobbio, Matteucci e

\footnotetext{
2 LAKATOS, Eva Maria; MARCONI, Marina de Andrade. Fundamentos de metodologia científica. 5 ed. São Paulo: Atlas, 2000. p. 106-109.
} 
TODESCHINI, Guilherme dos Santos. Redução do Parlamento brasileiro com inspiração no modelo dos Estados Unidos: a inconsistência objetiva do argumento em trânsito no Congresso Nacional brasileiro. Revista Eletrônica Direito e Política, Programa de Pós-Graduação Stricto Sensu em Ciência Jurídica da UNIVALI, Itajaí, v.14, n.2, $2^{\circ}$ quadrimestre de 2019. Disponível em: www.univali.br/direitoepolitica - ISSN 1980-7791

Pasquino apontam como um delicado problema de equilíbrio político, nos seguintes termos:

No âmbito dos Parlamentos que atuam como verdadeiros instrumentos representativos, o elemento distintivo está na "imagem" característica da sociedade política que eles são capazes de personificar. Em tal situação, a variável partidária tem naturalmente um peso decisivo. Uma das distinções mais importantes pelas conseqüências que implica para as outras atividades parlamentares é a existente entre Parlamentos aglutinadores da demanda política e Parlamentos pouco aglutinadores, ou seja, entre Parlamentos que concedem ampla margem a todas as instâncias mesmo particulares, e Parlamentos capazes de selecionar e sintetizar as demandas, "agregando-as" em alternativas políticas de certa amplitude. Um delicado problema de equilíbrio político é o de conciliar esta exigência de agregação com a exigência, também importante, de manter no Parlamento um elevado grau de transparência do pluralismo existente na sociedade, isto é, de evitar o risco de uma representação demasiado redutiva. ${ }^{3}$

No que se refere a escolhas relacionadas a esse equilíbrio político, as proposições legislativas em exame vão na linha da ideia de redução do número de membros do Poder Legislativo.

De 1999 a 2018 foram apresentadas, no Congresso Nacional brasileiro, ao menos 8 (oito) proposições legislativas com a finalidade de redução do número de parlamentares federais (tanto da câmara alta, quanto da câmara baixa). São elas as Propostas de Emenda Constitucional 170/1999, 519/2006, 280/2008 e 431/2018 iniciadas na Câmara dos Deputados, e, iniciadas no Senado Federal, as Propostas de Emenda Constitucional 67/2007, 38/2016 e 431/2018, e o Projeto de Lei Complementar no 251/2015.

No Brasil, o número de Deputados Federais é determinado em Lei Complementar (conforme art. 45, § 10, da Constituição Federal de $1988^{4}$ ), e está estabelecido, hoje, em até 513 (nos termos do art. $1^{0}$ da Lei Complementar Federal no

\footnotetext{
${ }^{3}$ BOBBIO, Norberto; MATTEUCCI, Nicola; PASQUINO, Gianfranco. Dicionário de política. Tradução de Carmen C. Varriale e João Ferreira, Revisão geral João Ferreira e Luís Guerreiro Pinto Cacais. 1 ed. vol. 1. Brasília: Editora Universidade de Brasília, 1998. p. 884.

4 BRASIL. Constituição da República Federativa do Brasil de 1988, de 5 de outubro de 1988. Disponível em: <http://www.planalto.gov.br/ccivil_03/Constituicao/Constituicao.htm>. Acesso em 4 jan. 2019.
} 
TODESCHINI, Guilherme dos Santos. Redução do Parlamento brasileiro com inspiração no modelo dos Estados Unidos: a inconsistência objetiva do argumento em trânsito no Congresso Nacional brasileiro. Revista Eletrônica Direito e Política, Programa de Pós-Graduação Stricto Sensu em Ciência Jurídica da UNIVALI, Itajaí, v.14, n.2, $2^{\circ}$ quadrimestre de 2019. Disponível em: www.univali.br/direitoepolitica - ISSN 1980-7791

78/19935). Já o número de Senadores é fixado em 3 por Estado e pelo Distrito Federal, conforme art. 46, § 10, da Constituição Federal de 1988.

As referidas proposições objetivam ou objetivavam (uma vez que algumas ainda tramitam, e outras já foram arquivadas) a redução do número de parlamentares nas seguintes proporções: redução do número de Deputados Federais para 380 (PEC 170/1999 da Câmara dos Deputados ${ }^{6}$ ); redução do número de Deputados Federais para 450 (PEC 519/2006 da Câmara dos Deputados ${ }^{7}$ ); redução do número de Deputados Federais para 250 (PEC 280/2008 da Câmara dos Deputados ${ }^{8}$ ); redução do número de Senadores de 3 para 2 por Estado e para o Distrito Federal (PEC 431/2018 da Câmara dos Deputados ${ }^{9}$ e PEC 67/2007 do Senado Federal ${ }^{10}$ ); redução do número de Deputados Federais para até 405 (PEC 38/2016 do Senado Federa ${ }^{11}$ ); redução do número de deputados federais para até 385 , e do número de Senadores de 3 para 2 por Estado e para o Distrito Federal (PEC 106/2015 do Senado Federal ${ }^{12}$ ); e redução do número de Deputados Federais para até 300 (Projeto de Lei Complementar no 251/2015 do Senado Federal ${ }^{13}$ ).

No que se refere às exposições de motivos dessas proposições, bem como a algumas das manifestações de outros parlamentares em etapas posteriores do processo legislativo, observa-se que, de regra, as justificativas para a aprovação dos projetos tinham como um de seus pilares de sustentação o entendimento de que há um número excessivo de parlamentares no Brasil. $\mathrm{E}$, diante desse número entendido como excessivo, alegava-se que a redução do número de parlamentares

\footnotetext{
5 BRASIL. Diário Oficial da União. Seção 1. Ano CXXXII, no 3, Brasília-DF, 5 jan. 1994. p. 1, col. 1.

6 Disponível em <http://www.camara.gov.br/proposicoesWeb/prop_mostrarintegra?codteor=1014858\&filename= Dossie+-PEC+170/1999>. Acesso em 4 jan. 2019.

7 BRASIL. Diário da Câmara dos Deputados. Ano LXI, no 053, Brasília-DF, 29 mar. 2006. p. 15558, col. 1.

8 BRASIL. Diário da Câmara dos Deputados. Ano LXIII, no 122, Brasília-DF, 6 ago. 2008. p. 34835, col. 1.

9 BRASIL. Diário da Câmara dos Deputados. Ano LXXIII, no 107, Brasília-DF, 6 jul. 2018. p. 83.

10 BRASIL. Diário do Senado Federal. Ano LXII, no 119, Brasília-DF, 10 ago. 2007. p. 27127, col. 1.

11 BRASIL. Diário do Senado Federal. Ano LXXI, no 106, Brasília-DF, 14 jul. 2016. p. 489.

12 BRASIL. Diário do Senado Federal. Ano LXX, no 113, Brasília-DF, 17 jul. 2015. p. 280.

13 BRASIL. Diário do Senado Federal. Ano LXX, no 059, Brasília-DF, 30 abr. 2015. p. 34.
} 
TODESCHINI, Guilherme dos Santos. Redução do Parlamento brasileiro com inspiração no modelo dos Estados Unidos: a inconsistência objetiva do argumento em trânsito no Congresso Nacional brasileiro. Revista Eletrônica Direito e Política, Programa de Pós-Graduação Stricto Sensu em Ciência Jurídica da UNIVALI, Itajaí, v.14, n.2, $2^{\circ}$ quadrimestre de 2019. Disponível em: www.univali.br/direitoepolitica - ISSN 1980-7791

teria por consequência a redução de gasto público com sustento do Poder Legislativo.

Isso se pode observar, por exemplo, da exposição de motivos da PEC no 519/2006 da Câmara dos Deputados, na qual fala-se em "excessivo número de Deputados"14. Na PEC 280/2008 da Câmara dos Deputados, consta da justificação da proposta o entendimento expresso dos propositores de que "o atual número de Deputados nos parece excessivo"15. Consta, da justificativa do Projeto de Lei Complementar no 251/2015 do Senado, a afirmação de que "o Poder Legislativo não precisa ser "inchado" como é hoje, revelando-se excessivo o total de 513 deputados federais"16. Já na justificativa da PEC 38/2016 do Senado Federal, a exposição de motivos da proposição a anuncia como parte de um "esforço de redução do Estado brasileiro e conseqüente diminuição dos gastos públicos"17.

Em três desses projetos, contudo, observa-se que se utilizou, como argumento defensivo da proposta, a comparação do número de parlamentares no Brasil com o número de parlamentares nos Estados Unidos. A comparação é feita, aparentemente, no sentido de que, como nos Estados Unidos o número de parlamentares é menor do que no Brasil (não só proporcionalmente em relação à população, mas também em números totais), deveria no Brasil adotar-se a mesma lógica, reduzindo-se o número de parlamentares. Cabe esclarecer, nesse ponto, que as comparações indicadas aparentam tem essa finalidade porque, apesar de não haver indicação expressa nesse sentido, afiguras-se razoável aferir-se que tais informações não foram inseridas naqueles documentos de modo despretensioso ou como meros dados comparativos sem valor argumentativo para a defesa das propostas, mas sim para justificar sua aprovação.

Na PEC 67/2007 do Senado Federal (da qual consta, na exposição de motivos, referência dos propositores a um "esforço de redução dos quantitativos de parlamentares que compõem o Poder Legislativo no Brasil, para os fins de redução

\footnotetext{
${ }^{14}$ BRASIL. Diário da Câmara dos Deputados. Ano LXI, no 053, Brasília-DF, 29 mar. 2006. p. 15558, col. 2.

15 BRASIL. Diário da Câmara dos Deputados. Ano LXIII, no 122, Brasília-DF, 6 ago. 2008. p. 34835, col. 2.

16 BRASIL. Diário do Senado Federal. Ano LXX, no 059, Brasília-DF, 30 abr. 2015. p. 34.

17 BRASIL. Diário do Senado Federal. Ano LXXI, no 106, Brasília-DF, 14 jul. 2016. p. 490.
} 
TODESCHINI, Guilherme dos Santos. Redução do Parlamento brasileiro com inspiração no modelo dos Estados Unidos: a inconsistência objetiva do argumento em trânsito no Congresso Nacional brasileiro. Revista Eletrônica Direito e Política, Programa de Pós-Graduação Stricto Sensu em Ciência Jurídica da UNIVALI, Itajaí, v.14, n.2, $2^{\circ}$ quadrimestre de 2019. Disponível em: www.univali.br/direitoepolitica - ISSN 1980-7791

do aparato estatal e dos gastos públicos"18), o relator da proposição na Comissão de Constituição e Justiça da casa, em parecer pela sua admissibilidade, relaciona seu mérito do seguinte modo à experiência dos Estados Unidos:

A necessidade de redução de custos do setor público, defendida com insistência por vários setores da sociedade, reforça os argumentos favoráveis à proposição. Experiências bem sucedidas de outras democracias, como a norteamericana, cujos estados elegem dois representantes para o Senado, independentemente de sua população, também realçam a importância da PEC em exame ${ }^{19}$.

Já na PEC 106/2015, consta da exposição de motivo da proposição a seguinte consideração em termos de comparação do Brasil com os Estados Unidos:

Consideramos, por outro lado, que nem mesmo as dimensões continentais do Brasil e a complexidade de nossa sociedade justificam a eleição de três representantes por Estado e pelo Distrito Federal para esta Casa. Mencionamos, a título de exemplo, os Estados Unidos da América, país igualmente extenso, cujos estados elegem dois senadores cada um.

Ante o exposto, a proposta de emenda à Constituição que ora apresentamos tem por objetivo reduzir o número de assentos em um terço no Senado Federal e em 25\% da Câmara dos Deputados. ${ }^{20}$

Por fim, na PEC 431/2018 da Câmara dos Deputados, caso bastante significativo para a abordagem do argumento objeto da presente pesquisa, consta da exposição de motivos da proposição a seguinte manifestação:

(...) propomos a redução de aproximadamente 23, 19\% (vinte e três inteiros e dezenove centésimos por cento) do número de Deputados Federais; a de 33,33\% (trinta e três inteiros e trinta e três centésimos por cento) do número de Senadores da República; a redução, em média e aproximadamente, de $24 \%$ (vinte e quatro por cento) do número dos Deputados Estaduais e Distritais, variando de acordo com cada ente, em razão desse montante ser diretamente influenciado, em maior ou menor escala, pela redução do número de Deputados Federais.

\footnotetext{
18 BRASIL. Diário do Senado Federal. Ano LXII, no 119, Brasília-DF, 10 ago. 2007. p. 27127, col. 2. 19 Disponível em: <https://legis.senado.leg.br/sdleggetter/documento dm $=4416785 \& t s=1543058148603 \&$ disposition=inline $>$, p. 2. Acesso em 17 dez. 2018.

20 BRASIL. Diário do Senado Federal. Ano LXX, no 113, Brasília-DF, 17 jul. 2015. p. 282.
} 
TODESCHINI, Guilherme dos Santos. Redução do Parlamento brasileiro com inspiração no modelo dos Estados Unidos: a inconsistência objetiva do argumento em trânsito no Congresso Nacional brasileiro. Revista Eletrônica Direito e Política, Programa de Pós-Graduação Stricto Sensu em Ciência Jurídica da UNIVALI, Itajaí, v.14, n.2, 20 quadrimestre de 2019. Disponível em: www.univali.br/direitoepolitica - ISSN 1980-7791

A título comparativo, vale mencionar o exemplo dos Estados Unidos da América, em que 435 (quatrocentos e trinta e cinco) membros da Câmara dos Representantes, órgão equivalente à nossa Câmara dos Deputados, representam uma população de pouco menos de 327 milhões de habitantes. ${ }^{21}$

Cabe ressaltar, ainda (o que explica a referência aos Deputados Estaduais na exposição de motivos da PEC 431/2018 da Câmara dos Deputados), que, coeteris paribus ${ }^{22}$, qualquer proposta resultante na redução do número de Deputados Federais gera, por consequência, também a redução do número de Deputados Estaduais, uma vez que o art. 27 da Constituição Federal de 1988 regula o número desses com base no número daqueles.

É possível afirmar-se, assim, com base no teor e na exposição de motivos da PEC 431/2018 da Câmara dos Deputados (levando em consideração as referências ao modelo norte-americano e à redução também do número de Deputados Estaduais no Brasil), em termos gerais ${ }^{23}$, que está sendo proposta, no Congresso Nacional brasileiro, a redução do número de Senadores, Deputados Federais e Deputados Estaduais com base - alegadamente - na experiência de proporcionalidade representativa parlamentar dos Estados Unidos, que teria um parlamento mais enxuto e, consecutivamente, uma menor densidade ${ }^{24}$ representativa do que no Brasil.

O objetivo do presente trabalho, é demonstrar, mediante apresentação dos resultados de pesquisa e posterior cruzamento de dados numéricos, que,

21 BRASIL. Diário da Câmara dos Deputados. Ano LXXIII, no 107, Brasília-DF, 6 jul. 2018. p. 84.

22 Coeteris paribus, conforme Paulo Sandroni, trata-se de uma "Expressão em latim que significa "permanecendo constantes todas as demais variáveis". Muito utilizada em economia quando se deseja avaliar as consequências de uma variável sobre outra, supondo-se as demais inalteradas." (SANDRONI, Paulo (Org.). Novíssimo Dicionário de Economia. São Paulo: Editora Best Seller, 1999. p. 107 e 78)

23 Em termos gerais no que se refere à ideia geral de redução do número de parlamentares. Necessário esclarecer, contudo, que a redução do número de Senadores (diferentemente do que ocorre na hipótese de redução do número de Deputados Federais) não resulta automaticamente na redução do número de Deputados Estaduais.

${ }^{24}$ A expressão densidade representativa, no presente texto, busca traduzir a seguinte ideia: quanto maior o número médio de habitantes representados por um parlamentar, menor a densidade representativa naquela esfera de representação política; quanto menor o número médio de habitantes representados por um parlamentar, maior a densidade representativa naquela esfera de representação política. 
TODESCHINI, Guilherme dos Santos. Redução do Parlamento brasileiro com inspiração no modelo dos Estados Unidos: a inconsistência objetiva do argumento em trânsito no Congresso Nacional brasileiro. Revista Eletrônica Direito e Política, Programa de Pós-Graduação Stricto Sensu em Ciência Jurídica da UNIVALI, Itajaí, v.14, n.2, $2^{\circ}$ quadrimestre de 2019. Disponível em: www.univali.br/direitoepolitica - ISSN 1980-7791

entretanto, não é verdadeiro o argumento de que nos Estados Unidos a representação parlamentar é mais enxuta do que no Brasil - mas sim o contrário: os Estados Unidos têm uma densidade de representação parlamentar maior do que a brasileira.

Pertinente esclarecer-se, contudo, antes de se passar ao exame dos dados coletados em pesquisa, que o argumento justificador das propostas em trâmite no Congresso Nacional brasileiro ser inverídico não importa na aferição de uma inadequação jurídica, mas sim de uma inadequação circunscrita aos planos lógico e político. Isso porque o critério da intenção do legislador (expressa, nesses casos, nas justificativas das propostas) não é apto à afetação da validade de norma jurídica promulgada, bem como é apontado como método questionável e insuficiente de interpretação jurídica ${ }^{25}$. A inadequação da proposta, nos casos aqui examinados, reside nos planos lógico e político porque assentada em premissa que não condiz com a realidade dos fatos ${ }^{26}$ (conforme levantamento estatístico que embasa o presente estudo).

Pertinente esclarecer-se, também, que o presente estudo não considera o âmbito municipal de representação parlamentar devido à grande dificuldade de coleta de dados relativos a essas circunscrições com o mesmo nível de confiabilidade que se pode ter na coleta dos dados relativos à representação federal e estadual, levandose em consideração o elevado número de Municípios em ambos os países ${ }^{27}$. Cabe ressaltar, ainda, que limitação do recorte do presente trabalho aos âmbitos federal e estadual se justifica devido à circunstância de que as propostas apresentadas no Congresso Nacional brasileiro (as quais veiculam o argumento objeto de exame) têm o potencial de afetar a proporcionalidade representativa parlamentar nesses dois âmbitos, mas não nos Municípios brasileiros - uma vez que, nessa esfera de poder, o número de parlamentares é fixado em quantitativos exatos conforme a população representada, conforme art. 29, IV, da Constituição Federal de 1988 (e

${ }^{25}$ LARENTZ, Karl. Metodologia da Ciência do Direito. Tradução de José Lamego. 3 ed. Lisboa: Fundação Calouste Gulbenkian, 1997. p. 445-450 e 462-469.

${ }^{26}$ ALEXY, Robert. Teoria da argumentação jurídica. Tradução de Zilda Hutchinson Schild Silva. São Paulo: Editora Landy, 2001. p. 187.

27 Tal circunstância, inclusive, autorizaria a alegação de que a conclusão do presente estudo tem natureza parcial, uma vez que não considera um dos três âmbitos de representação parlamentar. 
TODESCHINI, Guilherme dos Santos. Redução do Parlamento brasileiro com inspiração no modelo dos Estados Unidos: a inconsistência objetiva do argumento em trânsito no Congresso Nacional brasileiro. Revista Eletrônica Direito e Política, Programa de Pós-Graduação Stricto Sensu em Ciência Jurídica da UNIVALI, Itajaí, v.14, n.2, $2^{\circ}$ quadrimestre de 2019. Disponível em: www.univali.br/direitoepolitica - ISSN 1980-7791

não com base no número de parlamentares de outra esfera, tal como ocorre com o número de deputados estaduais em relação ao número de deputados federais).

\section{DADOS DE PESQUISA}

Buscou-se verificar, por meio da pesquisa, a veracidade do argumento de que a densidade representativa parlamentar nos Estados Unidos é realmente menor do que no Brasil (tal como afirmado por congressistas brasileiros). Coletou-se, para tanto, dados relativos à população total do Brasil e dos Estados Unidos, bem como dados relativos ao número de parlamentares de cada um dos países nos planos federal e estadual - os quais foram, posteriormente, cruzados para extração de resultados.

Alguns esclarecimentos anteriores, contudo, são pertinentes. Apesar de ambos os países possuírem, em comum, a estrutura federativa e parlamentos federais bicamerais, suas arquiteturas federativas, no que se refere ao âmbito da representação parlamentar, possui algumas pontuais diferenças ${ }^{28}$.

Uma dessas diferenças é a de que, enquanto nos Estados Unidos a estrutura que abriga a capital nacional (Distrito de Columbia) não tem representantes com poder deliberativo no Senado ou na Casa dos Representantes, no Brasil a estrutura que abriga a capital nacional (Distrito Federal) é considerada um ente federativo ${ }^{29}$, e possui representação tanto nas duas casas do Congresso Nacional na mesma proporção que os demais estados da federação ${ }^{30}$, quanto tem seu próprio parlamento local configurado tal como o parlamento dos demais Estados - com as diferenças, em relação àqueles, de que cumula competência para deliberação sobre matéria de competência legislativa e administrativa municipal (uma vez que o Distrito Federal não é divido em Municípios), e de que o ente é regido por Lei Orgânica com quórum deliberativo para alteração diverso do definido para as

\footnotetext{
${ }^{28} \mathrm{Aborda}-\mathrm{se}$, no texto, somente as diferenças identificadas como relevantes para o exame objetivo do argumento em análise. Existem, contudo, outras diferenças nos sistemas - tal como, por exemplo, o fato de que nos Estados Unidos o sistema de eleição dos parlamentares é distrital, enquanto no Brasil o sistema de eleição de Deputados Federais e Estaduais é proporcional.

${ }^{29}$ Art. 10, caput, da Constituição Federal de 1988.

${ }^{30}$ Arts. 45, § 10, e 46, § 10, da Constituição Federal de 1988.
} 
TODESCHINI, Guilherme dos Santos. Redução do Parlamento brasileiro com inspiração no modelo dos Estados Unidos: a inconsistência objetiva do argumento em trânsito no Congresso Nacional brasileiro. Revista Eletrônica Direito e Política, Programa de Pós-Graduação Stricto Sensu em Ciência Jurídica da UNIVALI, Itajaí, v.14, n.2, $2^{\circ}$ quadrimestre de 2019. Disponível em: www.univali.br/direitoepolitica - ISSN 1980-7791

Constituições Estaduais ${ }^{31}$. Assim, para os fins da presente pesquisa, computou-se os parlamentares e a população do Distrito Federal no Brasil, e não computou-se o delegado e a população do Distrito de Columbia nos Estados Unidos.

Cabe ressaltar, também, que não se computou, nos dados de pesquisa relativos aos Estados Unidos, além da população e dos congressistas do Distrito de Columbia, também a população e os congressistas de Porto Rico, de Guam, de Ilhas Virgens, de Samoa Americana, e de Ilhas Mariana. Cada um deles possui um membro na Casa dos Representantes, com poderes parlamentares restritos ${ }^{32}$. Referida exclusão se deu (considerando que o trabalho objetiva cruzar dados de população com número de representantes políticos) em razão do restrito poder deliberativo desses agentes no parlamento, bem como da desproporcionalidade em relação à população por eles representada (uma vez que o número é sempre de um Delegado, independentemente do contingente populacional representado).

Outra diferença é a de que, enquanto no Brasil a estrutura dos parlamentos estaduais é necessariamente unicameral (conforme art. 27 da Constituição Federal de 1988), nos Estado Unidos somente um dos parlamentos estaduais é unicameral (no Estado de Nebraska), sendo os demais bicamerais - compostos por uma Casa de Representantes estadual, e um Senado estadual. Considerou-se, assim, no cômputo dos dados, como parlamentares estaduais, a soma dos parlamentares de ambas as casas legislativas de cada um desses 49 Estados, e, no Nebraska (obviamente), só os membros do parlamento unicameral existente.

Feitos os esclarecimentos, passa-se ao relato do perfil da pesquisa.

Coletou-se, para posterior cruzamento de dados, o número total de Senadores, de Deputados Federais e de Deputados Estaduais ou Distritais existentes no Brasil, e o número total de representantes estaduais e federais análogos nos Estados Unidos (membros das Casas dos Representantes e dos Senados, nos níveis federal

\footnotetext{
${ }^{31}$ Arts. 32, caput, § $1^{\circ}$ e $\S 30$, e art. 25, caput, da Constituição Federal de 1988.

32 Conforme § 25a (para o Distrito de Columbia), §§ 891 a 894 (para Porto Rico), § 1711 (para Guam e Ilhas Virgens), § 1731 (para Samoa Americana) e § 1751 (para Ilhas Mariana), do United States Code, disponível em <http://uscode.house.gov/browse/prelim@title48\&edition=prelim>, acesso em 18 dez. 2018.
} 
TODESCHINI, Guilherme dos Santos. Redução do Parlamento brasileiro com inspiração no modelo dos Estados Unidos: a inconsistência objetiva do argumento em trânsito no Congresso Nacional brasileiro. Revista Eletrônica Direito e Política, Programa de Pós-Graduação Stricto Sensu em Ciência Jurídica da UNIVALI, Itajaí, v.14, n.2, $2^{\circ}$ quadrimestre de 2019. Disponível em: www.univali.br/direitoepolitica - ISSN 1980-7791

e estadual). Após, coletou-se o contingente populacional dos dois países, e de cada um de seus estados ${ }^{33}$.

As fontes utilizadas na pesquisa, para definição dos dados de contingente populacional, foram os números divulgados pelos censos populacionais do Brasil ${ }^{34}$ e dos Estados Unidos ${ }^{35}$ - utilizando-se, em ambos os casos, para fins de adequação comparativa, os contingentes populacionais estimados para julho de 2017.

Para a definição dos números de parlamentares no Brasil, utilizou-se o número de 513 para Deputados Federais (estabelecido limite máximo pela Lei Complementar Federal no 78/1993), o número de 81 para Senadores (resultante da aplicação da regra definida no art. 46, $\S 10$, da Constituição Federal de 1988), e os números constantes do sistema de divulgação de candidaturas do Tribunal Superior Eleitoral relativos às eleições de 2018 para definição dos quantitativos de Deputados Estaduais e Distritais ${ }^{36}$. Para a definição do número de parlamentares nos Estados Unidos, utilizou-se o número de 435 para os membros da Casa dos Representantes do Congresso Nacional ${ }^{37}$, o número de 100 para os membros do Senado Federal (resultante da aplicação da regra definida na seção 3 do art. I da Constituição dos Estados Unidos), e o número de parlamentares indicados nos endereços eletrônicos de cada uma das casas legislativas dos 50 Estados para os membros das casas parlamentares estaduais ${ }^{38}$.

Cabe ressaltar que a definição do número de parlamentares estaduais nos Estados Unidos enfrentou alguns percalços. Primeiramente, a dificuldade de coleta de dados para fixação do número real de parlamentares, em termos de comparação

\footnotetext{
33 Incluindo-se o Distrito Federal do Brasil. Dados disponíveis em <ftp://ftp.ibge.gov.br/Estimativas_de_Populacao/Estimativas_2017/estimativa_dou_2017.pdf>, p. 1. Acesso em 18 dez. 2018.

${ }^{35}$ Dados disponíveis em <https://factfinder.census.gov/faces/tableservices/jsf/pages/productview.xhtml?pid=PEP_2017_ PEPANNRES\&src=pt>. Acesso em 18 dez. 2018.

${ }^{36}$ Dados disponíveis em <http://divulgacandcontas.tse.jus.br/divulga/\#/2018>. Acesso em 18 dez. 2018.

37 Quantidade informada como de membros da Casa dos Representantes no endereço eletrônico do órgão legislativo, disponível em <https://www.house.gov/representatives>. Acesso em 26 dez. 2018.

38 Para fins de otimização de análise, os endereços eletrônicos de cada uma dessas casas legislativas está indicado no quadro constante do Anexo 3 ao presente texto.
} 
TODESCHINI, Guilherme dos Santos. Redução do Parlamento brasileiro com inspiração no modelo dos Estados Unidos: a inconsistência objetiva do argumento em trânsito no Congresso Nacional brasileiro. Revista Eletrônica Direito e Política, Programa de Pós-Graduação Stricto Sensu em Ciência Jurídica da UNIVALI, Itajaí, v.14, n.2, 20 quadrimestre de 2019. Disponível em: www.univali.br/direitoepolitica - ISSN 1980-7791

com o Brasil, é a de que nos Estados Unidos não há um órgão central responsável pela administração do processo eleitoral (tal como no Brasil, onde tal tarefa compete à Justiça Eleitoral) do qual se possa, de uma fonte única e confiável, extrair os dados buscados. Outra dificuldade foi a de que, enquanto algumas Constituições Estaduais fixam o número de membros da Casa dos Representantes e do Senado locais (tal como a Constituição do Hawaii, que estabelece, em seu art. III, Seções 2 e 3, os números, respectivamente, de 25 Senadores e de 51 Representantes ${ }^{39}$ ), outras não fixam um número exato desses parlamentares, mas sim, por exemplo, limites máximos (tal como definido no art. III, §3, da Constituição do Estado de Louisiana, onde se fixa os números máximos de 39 Senadores e 105 Representantes ${ }^{40}$ ) ou limites mínimos e máximos (tal como o definido na Constituição de New Hampshire, que, em seu art. 9, estabelece que a Casa dos Representantes do Estado terá entre 375 e 400 membros ${ }^{41}$ ).

Optou-se, assim, por selecionar-se o número de parlamentares informados nos endereços eletrônicos das casas parlamentares estaduais (considerando-se o número de cadeiras existentes na casa legislativa, incluindo-se as cadeiras vagas). Como fonte subsidiária de consulta (para casos nos quais o endereço eletrônico da casa legislativa estava indisponível ou o número de parlamentares não claramente era informado ${ }^{42}$ ) utilizou-se a plataforma eletrônica Ballotpedia ${ }^{43}$. Cabe ressaltar, em relação ao modo de coleta de dados dos parlamentares estaduais nos Estados Unidos, que, ainda que eventualmente possa haver algumas incorreções no número fixado para os cálculos e comparações realizadas nesse trabalho em relação ao número real de parlamentares existentes, os números a que se chegou

\footnotetext{
${ }^{39}$ Dados disponíveis em <http://Irbhawaii.org/con/conart3.html>. Acesso em 26 dez. 2018.

${ }^{40}$ Dados disponíveis em <http://senate.la.gov/Documents/Constitution/Article3.htm>. Acesso em 26 dez. 2018.

41 Dados disponíveis em <https://www.nh.gov/glance/house.htm>. Acesso em 26 dez. 2018.

$42 \mathrm{O}$ que ocorreu em relacão a ambas as casas legislativas de Indiana, Kentucky, Oregon e South Carolina, às Casas dos Representantes de Flórida, Missouri e New Hampshire, ao Senado de Utah, e ao parlamento unicameral de Nebraska.

43 A plataforma Ballotpedia (acessível no endereço eletrônico <https://ballotpedia.org/Main_Page>) trata-se de uma enciclopédia eletrônica com informações sobre política dos Estados Unidos, patrocinada por Lucy Burns Institute. Para a extração subsidiária de dados relativos às casas parlamentares que não os disponibilizavam em seu endereço eletrônico (ou que tinham endereços eletrônicos com problemas técnicos de acesso), a fonte mostrou-se confiável devido ao fato de que os dados dela constantes são compatíveis com os dados constantes dos endereços eletrônicos das casas legislativas que informam o número de parlamentares.
} 
TODESCHINI, Guilherme dos Santos. Redução do Parlamento brasileiro com inspiração no modelo dos Estados Unidos: a inconsistência objetiva do argumento em trânsito no Congresso Nacional brasileiro. Revista Eletrônica Direito e Política, Programa de Pós-Graduação Stricto Sensu em Ciência Jurídica da UNIVALI, Itajaí, v.14, n.2, $2^{\circ}$ quadrimestre de 2019. Disponível em: www.univali.br/direitoepolitica - ISSN 1980-7791

são válidos para justificar a abordagem do argumento objeto de exame, uma vez que, se não idênticos, são muito próximos aos números reais, de modo a não haver interferência significativa para as comparações propostas entre a proporção de parlamentares e a população dos dois países, considerada a proporcionalidade dos resultados obtidos.

\section{DISCUSSÃO DOS DADOS DE PESQUISA}

Os dados coletados na pesquisa estão dispostos nos Anexos 1 e 2 ao presente texto. As informações lá constantes confirmam a afirmação de que a densidade representativa (proporção de parlamentares por habitantes), considerando-se tão somente os parlamentos federais, é menor nos Estados Unidos do que no Brasil uma vez que, enquanto nos Brasil há, em média, de 1 parlamentar federal para cada 349.598 habitantes, nos Estados Unidos a média é de 1 parlamentar federal para cada 598.178 habitantes. Quanto a tal aspecto, as afirmações constantes das proposições legislativas com trâmite no Congresso nacional brasileiro indicadas são coerentes.

Considerando-se, porém, além dos parlamentares federais, também os parlamentares estaduais de ambos os países, verifica-se não ser verdadeiro o argumento de que nos Estados Unidos a representação parlamentar é mais enxuta do que no Brasil. Os dados coletados demonstram que, enquanto no Brasil existe, em média, 1 parlamentar para cada 125.627 habitantes, nos Estados Unidos existe, em média, 1 parlamentar para cada 40.397 habitantes. Tal número indica, por exemplo, que o universo hipotético de habitantes representados por 1 parlamentar no Brasil (que teria, em média, 125.627 habitantes) é maior do que o universo hipotético de habitantes nos Estados Unidos representado por, em média, 3 parlamentares (que teria 121.191 habitantes).

Outra constatação que se pode fazer dos dados é a de que, considerando-se apenas a representação no plano estadual, enquanto nos Estados Unidos só em 3 dos 50 estados cada parlamentar representa, em média, mais de 100.000 habitantes, no Brasil cada parlamentar representa, em média, mais de 100.000 
TODESCHINI, Guilherme dos Santos. Redução do Parlamento brasileiro com inspiração no modelo dos Estados Unidos: a inconsistência objetiva do argumento em trânsito no Congresso Nacional brasileiro. Revista Eletrônica Direito e Política, Programa de Pós-Graduação Stricto Sensu em Ciência Jurídica da UNIVALI, Itajaí, v.14, n.2, $2^{\circ}$ quadrimestre de 2019. Disponível em: www.univali.br/direitoepolitica - ISSN 1980-7791

habitantes em 21 dos 27 estados $^{44}$. Ainda considerando-se tão somente o plano estadual, pode-se constatar, também, o aprofundamento dessa densidade representativa pelos seguintes dados: enquanto nos Estados Unidos ocorre de um parlamentar representar, em média, menos de 10.000 habitantes em 8 dos 50 estados (chegando ao caso de cada parlamentar representar, em média, 3.167 habitantes em New Hampshire), no Brasil isso não ocorre (sendo que, no com maior densidade representativa (Roraima), cada parlamentar representa, em média, 21.776 habitantes).

Também pode-se constatar, via análise dos dados coletados, que 18 (dezoito) Estados norte-americanos têm densidade representativa maior do que o Estado brasileiro com maior densidade representativa (Roraima). Por outro lado, considerando-se somente os Estados de ambos os países, constata-se que, dos 17 (dezessete) com menor densidade representativa, 16 (dezesseis) são brasileiros.

\section{CONSIDERAÇÕES FINAIS}

A partir de tais dados, é possível concluir-se que, considerando-se os planos de representação política dos parlamentos estaduais e federais, não é verdadeira a afirmação de que representação parlamentar nos Estados Unidos é mais enxuta do que no Brasil, mas sim o contrário: os números comprovam que, nos Estados Unidos, a representação parlamentar é mais densa do que no Brasil (exceto se considerado apenas o âmbito federal).

Assim, das duas uma: o exemplo dos Estados Unidos poderia ser apontado como modelo a ser seguindo em propostas de aumento do número de representantes parlamentares no Brasil, ou, se apontado em propostas de redução desse número, o poderia ser feito para indicação de modelo a não ser adotado. As propostas com trâmite no Congresso Nacional brasileiro (de adoção do modelo dos Estados Unidos para reduzir-se o número de parlamentares), contudo, não observam nenhuma dessas duas deduções que os números permitem, uma vez que partem de

${ }^{44}$ Incluindo-se o Distrito Federal. 
TODESCHINI, Guilherme dos Santos. Redução do Parlamento brasileiro com inspiração no modelo dos Estados Unidos: a inconsistência objetiva do argumento em trânsito no Congresso Nacional brasileiro. Revista Eletrônica Direito e Política, Programa de Pós-Graduação Stricto Sensu em Ciência Jurídica da UNIVALI, Itajaí, v.14, n.2, $2^{\circ}$ quadrimestre de 2019. Disponível em: www.univali.br/direitoepolitica - ISSN 1980-7791

premissas equivocadas no que se refere à dimensão do Poder Legislativo em relação à população dos Estados Unidos.

\section{REFERÊNCIA DAS FONTES CITADAS}

ALEXY, Robert. Teoria da argumentação jurídica. Tradução de Zilda Hutchinson Schild Silva. São Paulo: Editora Landy, 2001.

BALLOTPEDIA. Disponível em: https://ballotpedia.org/Main_Page. Acesso em 17 dez. 2018.

BOBBIO, Norberto; MATTEUCCI, Nicola; PASQUINO, Gianfranco. Dicionário de política. Tradução de Carmen C. Varriale e João Ferreira, Revisão geral João Ferreira e Luís Guerreiro Pinto Cacais. 1 ed. vol. 1. Brasília: Editora Universidade de Brasília, 1998.

Brasil. Constituição da República Federativa do Brasil de 1988. Brasília: Senado Federal, 2018.

BRASIL. Diário da Câmara dos Deputados. Ano LXI, no 053, Brasília-DF, 29 mar. 2006.

BRASIL. Diário da Câmara dos Deputados. Ano LXIII, no 122, Brasília-DF, 6 ago. 2008.

BRASIL. Diário da Câmara dos Deputados. Ano LXXIII, no 107, Brasília-DF, 6 jul. 2018.

BRASIL. Diário do Senado Federal. Ano LXII, nº 119, Brasília-DF, 10 ago. 2007.

BRASIL. Diário do Senado Federal. Ano LXX, nº 059, Brasília-DF, 30 abr. 2015.

BRASIL. Diário do Senado Federal. Ano LXX, no 113, Brasília-DF, 17 jul. $2015 .$.

BRASIL. Diário do Senado Federal. Ano LXXI, no 106, Brasília-DF, 14 jul. 2016.

BRASIL. Diário Oficial da União. Seção 1. Ano CXXXII, n○ 3, Brasília-DF, 5 jan. 1994.

BRASIL. Parecer Senador Demóstenes Torres. Disponível em: $<$ https://legis.senado.leg.br/sdleggetter/documento?dm $=4416785 \& t s=1543058148603 \&$ disposition $=$ inline $>$, p. 2 . Acesso em 17 dez. 2018.

BRASIL. IBGE. Estimativas da população residente no Brasil<ftp://ftp.ibge.gov.br/Estimativas_de_Populacao/Estimativas_2017/estimat iva_dou_2017.pdf>. Acesso em 18 dez. 2018. 
TODESCHINI, Guilherme dos Santos. Redução do Parlamento brasileiro com inspiração no modelo dos Estados Unidos: a inconsistência objetiva do argumento em trânsito no Congresso Nacional brasileiro. Revista Eletrônica Direito e Política, Programa de Pós-Graduação Stricto Sensu em Ciência Jurídica da UNIVALI, Itajaí, v.14, n.2, $2^{\circ}$ quadrimestre de 2019. Disponível em: www.univali.br/direitoepolitica - ISSN 1980-7791

BRASIL. Tribunal superior eleitoral. Ddisponível em <http://divulgacandcontas.tse.jus.br/divulga/\#/2018>. Acesso em 18 dez. 2018.

EUA. The constitution of the state of hawaii. Disponivel em: <http://Irbhawaii.org/con/conart3.html>. Acesso em 26 dez. 2018.

EUA.

Senado.

Disponível

em:

<http://senate.la.gov/Documents/Constitution/Article3.htm>. Acesso em 26 dez. 2018.

UNITED STATES CENSUS. Annual Estimates of the Resident Populatio. Disponível em,. ;

<https://factfinder.census.gov/faces/tableservices/jsf/pages/productview.xhtml? pid=PEP_2017_PEPANNRES\&src=pt >. Acesso em $18 \mathrm{dez} .2018$.

NHGOV. State Constitution - House of Representatives. Disponíveis em:https://www.nh.gov/glance/house.htm. Acesso em 26 dez. 2018.

BRASIL. Câmara dos Deputadoas. Disponível em <http://www.camara.gov.br/proposicoesWeb/prop_mostrarintegra?codteor $=101$ 4858\&filename=Dossie+-PEC+170/1999>. Acesso em 4 jan. 2019.

LAKATOS, Eva Maria; MARCONI, Marina de Andrade. Fundamentos de metodologia científica. 5 ed. São Paulo: Atlas, 2000.

LARENTZ, Karl. Metodologia da Ciência do Direito. Tradução de José Lamego. 3 ed. Lisboa: Fundação Calouste Gulbenkian, 1997.

SANDRONI, Paulo (Org.). Novíssimo Dicionário de Economia. São Paulo: Editora Best Seller, 1999.

UNITED STATES CODE, disponível em <http://uscode.house.gov/browse/prelim@title48\&edition=prelim>, acesso em 18 dez. 2018.

\section{Anexo 1 - Comparativo de Proporcionalidade de Parlamentares por Habitantes}

\section{Quadro I}

\begin{tabular}{|c|c|c|c|c|c|}
\hline \multicolumn{6}{|c|}{ Brasil } \\
\hline \multirow[t]{2}{*}{ Ente Federado } & \multicolumn{2}{|c|}{ Parlamentares } & \multirow{2}{*}{$\begin{array}{c}\begin{array}{c}\text { Número Total } \\
\text { de }\end{array} \\
\text { Parlamentares }\end{array}$} & \multirow{2}{*}{\begin{tabular}{|c|} 
População \\
$(01 / 07 / 2017)^{*}$
\end{tabular}} & \multirow{2}{*}{$\begin{array}{c}\text { Proporção } \\
\text { População/Parlamentares } \\
\text { (arredondada) }\end{array}$} \\
\hline & $\begin{array}{c}\text { Deputado } \\
\mathrm{s}\end{array}$ & $\begin{array}{c}\text { Senadore } \\
\mathrm{S}\end{array}$ & & & \\
\hline Brasil - União & 513 & 81 & 594 & 207.660 .929 & 349.598 \\
\hline
\end{tabular}


TODESCHINI, Guilherme dos Santos. Redução do Parlamento brasileiro com inspiração no modelo dos Estados Unidos: a inconsistência objetiva do argumento em trânsito no Congresso Nacional brasileiro. Revista Eletrônica Direito e Política, Programa de Pós-Graduação Stricto Sensu em Ciência Jurídica da UNIVALI, Itajaí, v.14, n.2, $2^{\circ}$ quadrimestre de 2019. Disponível em: www.univali.br/direitoepolitica - ISSN 1980-7791

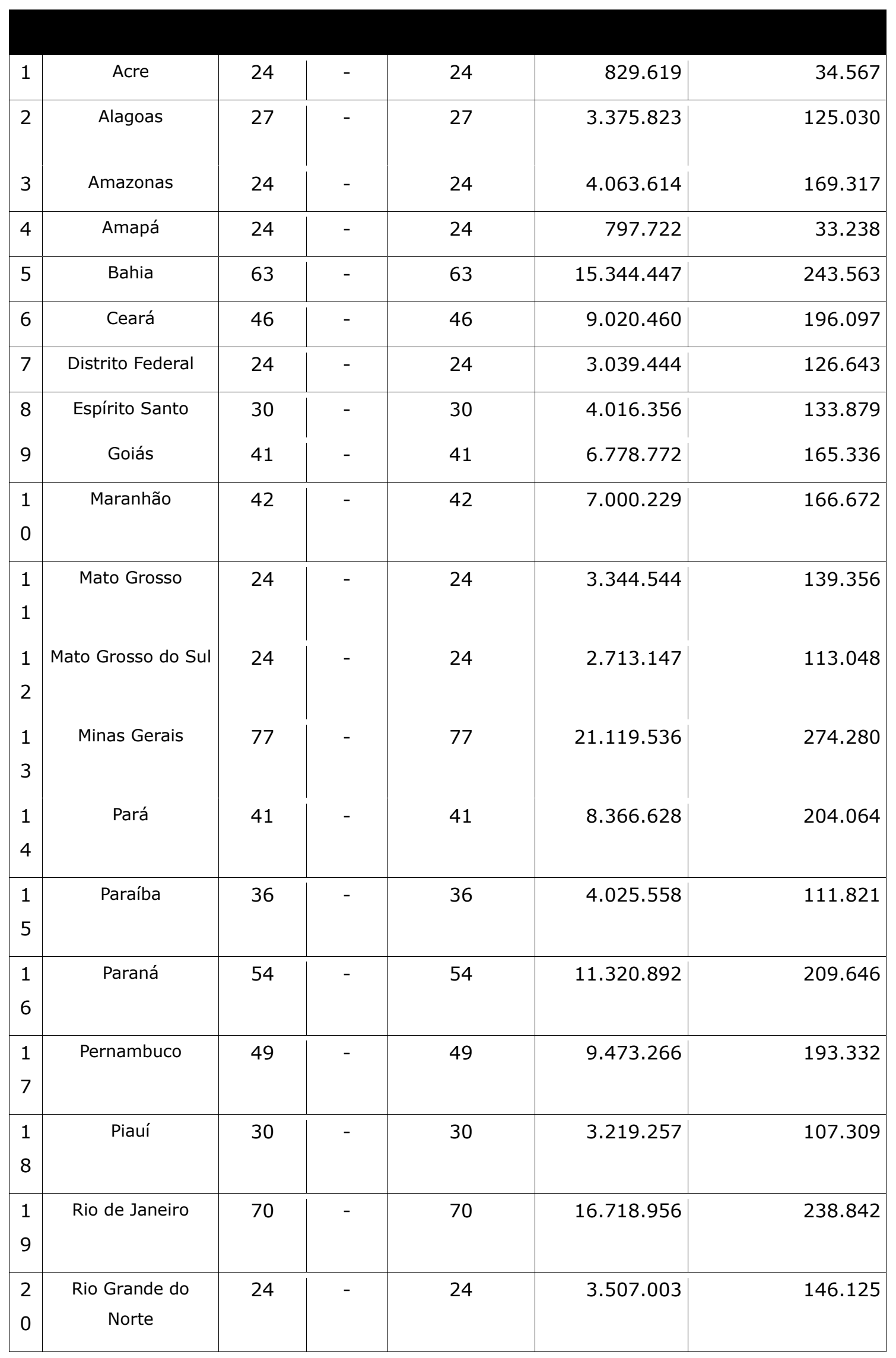


TODESCHINI, Guilherme dos Santos. Redução do Parlamento brasileiro com inspiração no modelo dos Estados Unidos: a inconsistência objetiva do argumento em trânsito no Congresso Nacional brasileiro. Revista Eletrônica Direito e Política, Programa de Pós-Graduação Stricto Sensu em Ciência Jurídica da UNIVALI, Itajaí, v.14, n.2, $2^{\circ}$ quadrimestre de 2019. Disponível em: www.univali.br/direitoepolitica - ISSN 1980-7791

\begin{tabular}{|c|c|c|c|c|c|c|}
\hline 2 & Rio Grande do Sul & 55 & - & 55 & 11.322 .895 & 205.871 \\
\hline $\begin{array}{l}2 \\
2\end{array}$ & Rondônia & 24 & - & 24 & 1.805 .788 & 75.241 \\
\hline $\begin{array}{l}2 \\
3\end{array}$ & Roraima & 24 & - & 24 & 522.636 & 21.776 \\
\hline $\begin{array}{l}2 \\
4\end{array}$ & Santa Catarina & 40 & - & 40 & 7.001 .161 & 175.029 \\
\hline $\begin{array}{l}2 \\
5\end{array}$ & São Paulo & 94 & - & 94 & 45.094 .866 & 479.733 \\
\hline $\begin{array}{l}2 \\
6\end{array}$ & Sergipe & 24 & - & 24 & 2.288 .116 & 95.338 \\
\hline $\begin{array}{l}2 \\
7\end{array}$ & Tocantins & 24 & - & 24 & 1.550 .194 & 64.591 \\
\hline & Total & - & - & 1653 & 207.660 .929 & 125.627 \\
\hline \multicolumn{7}{|r|}{ 17.pdf } \\
\hline
\end{tabular}

\section{Quadro II}

\begin{tabular}{|c|c|c|c|c|c|c|}
\hline \multicolumn{7}{|c|}{ Estados Unidos } \\
\hline \multicolumn{2}{|r|}{ Ente Federado } & \multicolumn{2}{|c|}{ Parlamentares } & \multirow{2}{*}{$\begin{array}{c}\text { Número total } \\
\text { de } \\
\text { Parlamentare } \\
\mathrm{s}\end{array}$} & \multirow{2}{*}{$\begin{array}{c}\text { População } \\
(01 / 07 / 2017) \\
* *\end{array}$} & \multirow{2}{*}{$\begin{array}{c}\text { Proporção } \\
\text { População/Parlamentare } \\
\text { s (arredondada) }\end{array}$} \\
\hline & & $\begin{array}{c}\text { Representante } \\
\mathrm{s}\end{array}$ & $\begin{array}{c}\text { Senadore } \\
\mathrm{s}\end{array}$ & & & \\
\hline \multicolumn{2}{|c|}{$\begin{array}{c}\text { Estados Unidos* - } \\
\text { União }\end{array}$} & 435 & 100 & 535 & $\begin{array}{r}320.025 .20 \\
6\end{array}$ & 598.178 \\
\hline 1 & Alabama & 105 & 35 & 140 & 4.874 .747 & 34.820 \\
\hline 2 & Alaska & 40 & 20 & 60 & 739.795 & 12.330 \\
\hline 3 & Arizona & 60 & 30 & 90 & 7.016 .270 & 77.959 \\
\hline 4 & Arkansas & 100 & 35 & 135 & 3.004 .279 & 22.254 \\
\hline 5 & Calofornia & 80 & 40 & 120 & 39.536 .653 & 329.472 \\
\hline
\end{tabular}


TODESCHINI, Guilherme dos Santos. Redução do Parlamento brasileiro com inspiração no modelo dos Estados Unidos: a inconsistência objetiva do argumento em trânsito no Congresso Nacional brasileiro. Revista Eletrônica Direito e Política, Programa de Pós-Graduação Stricto Sensu em Ciência Jurídica da UNIVALI, Itajaí, v.14, n.2, $2^{\circ}$ quadrimestre de 2019. Disponível em: www.univali.br/direitoepolitica - ISSN 1980-7791

\begin{tabular}{|c|c|c|c|c|c|c|}
\hline 6 & Colorado & 65 & 35 & 100 & 5.607 .154 & 56.072 \\
\hline 7 & Connecticut & 151 & 36 & 187 & 3.588 .184 & 19.118 \\
\hline 8 & Delaware & 41 & 21 & 62 & 961.939 & 15.515 \\
\hline 9 & Flórida & 120 & 40 & 160 & 20.984 .400 & 131.152 \\
\hline 10 & Geórgia & 180 & 56 & 236 & 10.429 .379 & 44.192 \\
\hline 11 & Hawaii & 51 & 25 & 76 & 1.427 .538 & 18.783 \\
\hline 12 & Idaho & 70 & 35 & 105 & 1.716 .943 & 16.352 \\
\hline 13 & Ilinois & 118 & 58 & 176 & 12.802 .023 & 72.739 \\
\hline 14 & Indiana & 100 & 50 & 150 & 6.666 .818 & 44.445 \\
\hline 15 & Iowa & 99 & 50 & 149 & 3.145 .711 & 21.112 \\
\hline 16 & Kansas & 125 & 40 & 165 & 2.913 .123 & 17.655 \\
\hline 17 & Kentucky & 100 & 38 & 138 & 4.454 .189 & 32.277 \\
\hline 18 & Louisiana & 105 & 39 & 144 & 4.684 .333 & 32.530 \\
\hline 19 & Maine & 155 & 35 & 190 & 1.335 .907 & 7.031 \\
\hline 20 & Maryland & 141 & 47 & 188 & 6.052 .177 & 32.192 \\
\hline 21 & Massachussets & 160 & 40 & 200 & 6.859 .819 & 34.299 \\
\hline 22 & Michigan & 110 & 38 & 148 & 9.962 .311 & 67.313 \\
\hline 23 & Minnesota & 134 & 66 & 200 & 5.576 .606 & 27.883 \\
\hline 24 & Mississipi & 122 & 52 & 174 & 2.984 .100 & 17.150 \\
\hline 25 & Missouri & 163 & 34 & 197 & 6.113 .532 & 31.033 \\
\hline 26 & Montana & 100 & 50 & 150 & 1.050 .493 & 7.003 \\
\hline 27 & Nebraska*** & \multicolumn{2}{|c|}{49} & 49 & 1.920 .076 & 39.185 \\
\hline 28 & Nevada & 42 & 21 & 63 & 2.998 .039 & 47.588 \\
\hline 29 & New Hampshire & 400 & 24 & 424 & 1.342 .795 & 3.167 \\
\hline 30 & New Jersey & 80 & 40 & 120 & 9.005 .644 & 75.047 \\
\hline 31 & New Mexico & 70 & 42 & 112 & 2.088 .070 & 18.643 \\
\hline 32 & New York & 150 & 63 & 213 & 19.849 .399 & 93.189 \\
\hline 33 & North Carolina & 120 & 50 & 170 & 10.273 .419 & 60.432 \\
\hline 34 & North Dakota & 94 & 47 & 141 & 755.393 & 5.357 \\
\hline 35 & Ohio & 99 & 33 & 132 & 11.658 .609 & 88.323 \\
\hline
\end{tabular}


TODESCHINI, Guilherme dos Santos. Redução do Parlamento brasileiro com inspiração no modelo dos Estados Unidos: a inconsistência objetiva do argumento em trânsito no Congresso Nacional brasileiro. Revista Eletrônica Direito e Política, Programa de Pós-Graduação Stricto Sensu em Ciência Jurídica da UNIVALI, Itajaí, v.14, n.2, $2^{\circ}$ quadrimestre de 2019. Disponível em: www.univali.br/direitoepolitica - ISSN 1980-7791

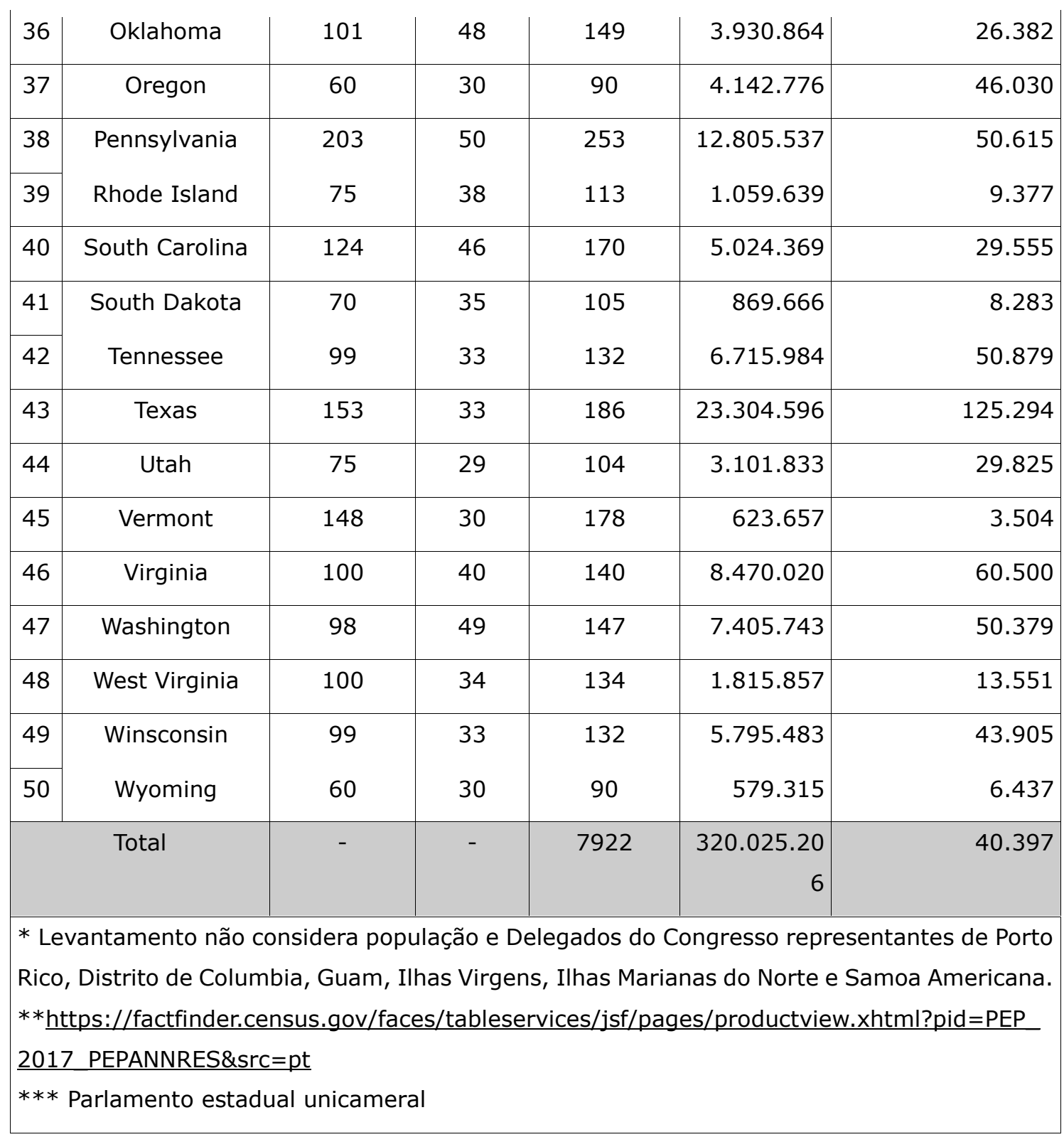


TODESCHINI, Guilherme dos Santos. Redução do Parlamento brasileiro com inspiração no modelo dos Estados Unidos: a inconsistência objetiva do argumento em trânsito no Congresso Nacional brasileiro. Revista Eletrônica Direito e Política, Programa de Pós-Graduação Stricto Sensu em Ciência Jurídica da UNIVALI, Itajaí, v.14, n.2, $2^{\circ}$ quadrimestre de 2019. Disponível em: www.univali.br/direitoepolitica - ISSN 1980-7791

\section{Anexo 2 - Gráficos comparativos do número de habitantes representados por parlamentar}

\section{Gráfico I - Número médio de habitantes representados por parlamentar, considerando-se o número total de parlamentares (estaduais e federais)}

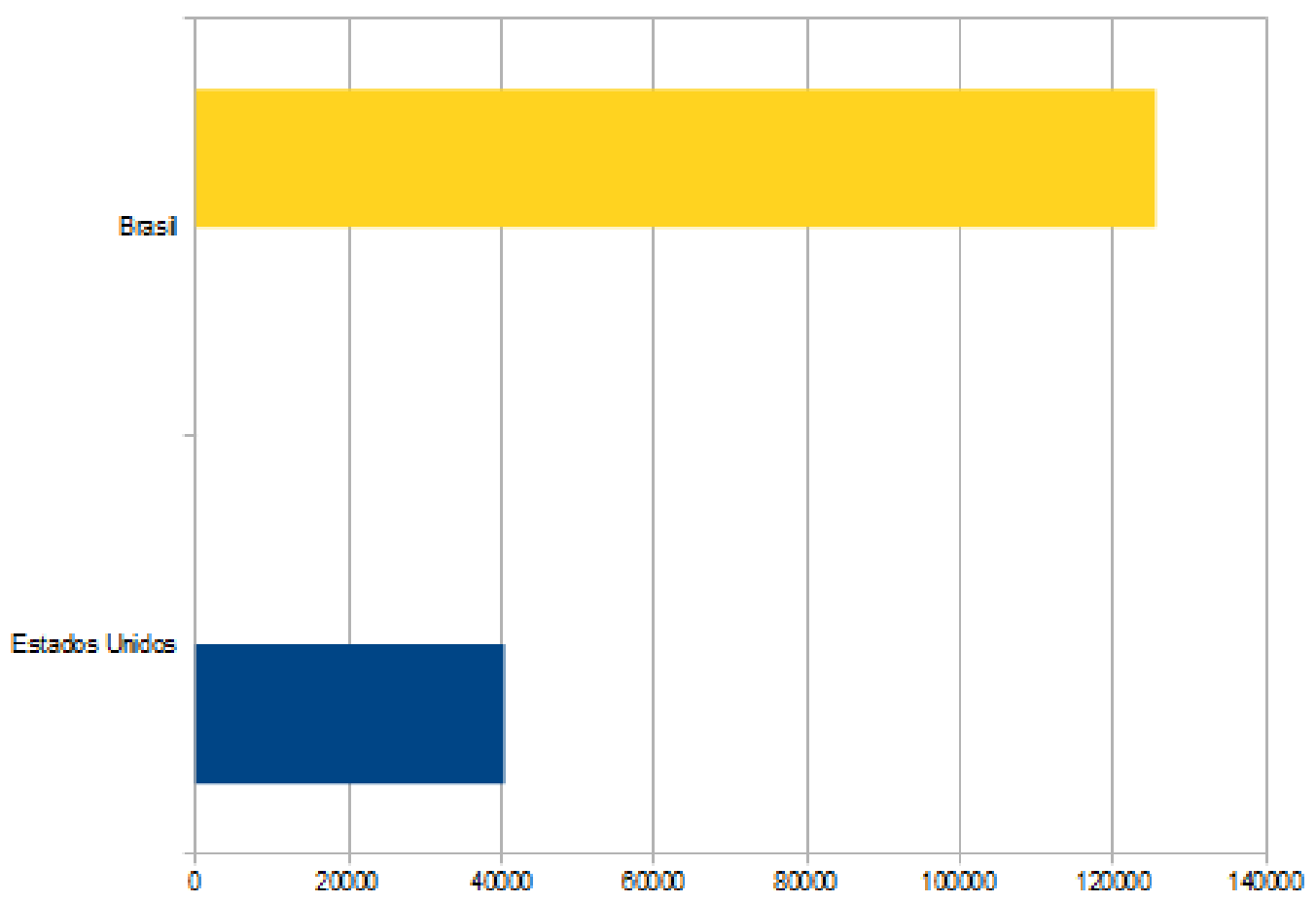


TODESCHINI, Guilherme dos Santos. Redução do Parlamento brasileiro com inspiração no modelo dos Estados Unidos: a inconsistência objetiva do argumento em trânsito no Congresso Nacional brasileiro. Revista Eletrônica Direito e Política, Programa de Pós-Graduação Stricto Sensu em Ciência Jurídica da UNIVALI, Itajaí, v.14, n.2, $2^{\circ}$ quadrimestre de 2019. Disponível em: www.univali.br/direitoepolitica - ISSN 1980-7791

\section{Gráfico II - Número médio de habitantes representados por parlamentar, considerando-se cada ente federativo}

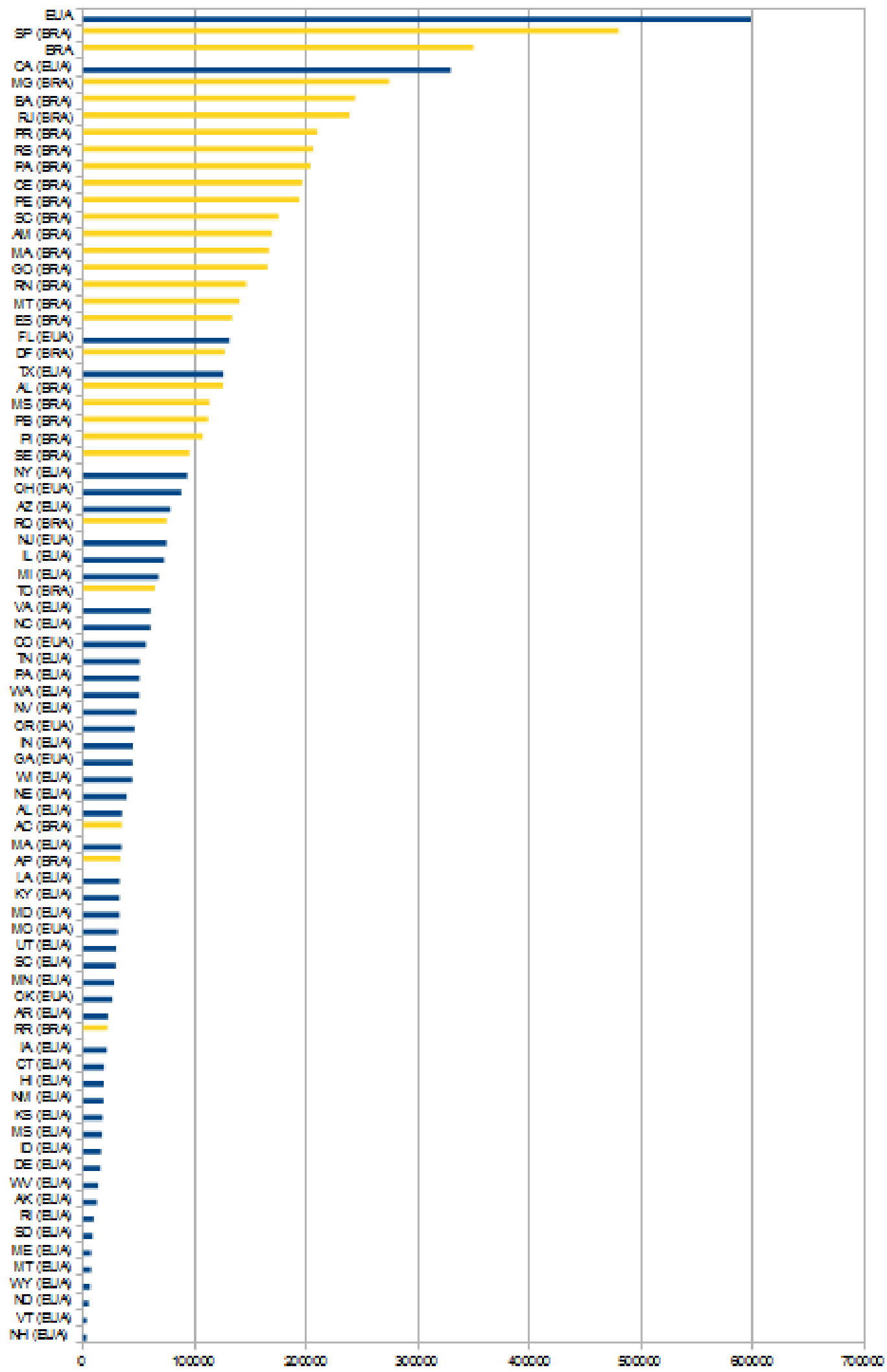


TODESCHINI, Guilherme dos Santos. Redução do Parlamento brasileiro com inspiração no modelo dos Estados Unidos: a inconsistência objetiva do argumento em trânsito no Congresso Nacional brasileiro. Revista Eletrônica Direito e Política, Programa de Pós-Graduação Stricto Sensu em Ciência Jurídica da UNIVALI, Itajaí, v.14, n.2, $2^{\circ}$ quadrimestre de 2019. Disponível em: www.univali.br/direitoepolitica - ISSN 1980-7791

\section{Anexo 3 - Endereços eletrônicos das Casas Legislativas dos Estados Unidos utilizados para extração de dados (Acesso 28 dez. 2018)}

\begin{tabular}{|c|c|c|c|}
\hline \multicolumn{4}{|c|}{ Estados Unidos } \\
\hline \multicolumn{2}{|c|}{ Ente Federado } & \multirow{2}{*}{\begin{tabular}{|l}
$\begin{array}{c}\text { Endereço eletrônico da Casa dos } \\
\text { Representantes estadual }\end{array}$ \\
$\begin{array}{l}\text { http://www.legislature.state.al.us/ } \\
\text { aliswww/ISD/House/ALRepresentat }\end{array}$ \\
$\underline{\text { ives.aspx }}$
\end{tabular}} & \multirow{2}{*}{\begin{tabular}{|l}
$\begin{array}{c}\text { Endereço eletrônico do Senado } \\
\text { estadual }\end{array}$ \\
$\begin{array}{l}\text { http://www.legislature.state.al.us/ } \\
\text { aliswww/ISD/Senate/ALSenators.a }\end{array}$ \\
$\underline{\text { spx }}$
\end{tabular}} \\
\hline 1 & Alaba & & \\
\hline 2 & ska & $p$ & http://akleg.g \\
\hline 3 & & $\begin{array}{c}\text { https://www.azleg.gov/MemberRos } \\
\underline{\text { ter/?body }=H}\end{array}$ & $\frac{\text { https://www.azleg.gov/MemberRos }}{\underline{\text { ter/?body }=\mathrm{S}}}$ \\
\hline 4 & Arkansas & $\begin{array}{l}\underline{\text { http://www.arkleg.state.ar.us/asse }} \\
\text { mbly/2019/2019R/Pages/Legislator } \\
\text { SearchResults.aspx?member=\&co } \\
\underline{\text { mmittee=All\&chamber=Representa }} \\
\underline{\text { tive }}\end{array}$ & $\begin{array}{l}\text { http://www.arkleg.state.ar.us/asse } \\
\text { mbly/2019/2019R/Pages/Legislator } \\
\underline{\text { SearchResults.aspx?member }=\& \text { co }} \\
\underline{\text { mmittee=All\&chamber }=\text { Senator }}\end{array}$ \\
\hline 5 & Calofornia & $\frac{\text { https://www.assembly.ca.gov/asse }}{\text { mblymembers }}$ & $\frac{\text { https://www.senate.ca.gov/senator }}{\underline{\mathrm{s}}}$ \\
\hline 6 & Colorado & $\begin{array}{l}\text { https://leg.colorado.gov/legislators } \\
\text { ?field chamber target id=1\&field } \\
\text { political affiliation target id=All\&s } \\
\text { ort bef combine=field last name } \\
\text { value } \% 20 \mathrm{ASC}\end{array}$ & $\begin{array}{l}\text { https://leg.colorado.gov/legislators } \\
\text { ?field chamber target id=2\&field } \\
\text { political affiliation target id=All\&s } \\
\text { ort bef combine=field last name } \\
\text { value } \% 20 \mathrm{ASC}\end{array}$ \\
\hline 7 & Connecticut & $\frac{\text { https://www.cga.ct.gov/asp/menu/ }}{\underline{\text { hlist.asp }}}$ & $\frac{\text { https://www.cga.ct.gov/asp/menu/ }}{\text { slist.asp }}$ \\
\hline 8 & Delaware & https://legis.delaware.gov/House & https://legis.delaware.gov/Senate \\
\hline 9 & ida & $\begin{array}{c}\text { https://ballotpedia.org/Florida Hou } \\
\text { se of Representatives }\end{array}$ & $\frac{\text { http://www.flsenate.gov/Senators/ }}{\text { \#Senators }}$ \\
\hline 10 & Geórgia & $\begin{array}{c}\text { http://www.house.ga.gov/Represe } \\
\text { ntatives/en- } \\
\text { US/HouseMembersList.aspx }\end{array}$ & $\begin{array}{l}\text { http://www.senate.ga.gov/senator } \\
\text { s/en-US/SenateMembersList.aspx }\end{array}$ \\
\hline 11 & Hawaii & $\begin{array}{l}\text { https://www.capitol.hawaii.gov/me } \\
\text { mbers/legislators.aspx?chamber }=H\end{array}$ & $\begin{array}{l}\text { https://www.capitol.hawaii.gov/me } \\
\text { mbers/legislators.aspx?chamber=S }\end{array}$ \\
\hline 12 & Idaho & https://legislature.idaho.gov/house & https://legislature.idaho.gov/senat \\
\hline
\end{tabular}


TODESCHINI, Guilherme dos Santos. Redução do Parlamento brasileiro com inspiração no modelo dos Estados Unidos: a inconsistência objetiva do argumento em trânsito no Congresso Nacional brasileiro. Revista Eletrônica Direito e Política, Programa de Pós-Graduação Stricto Sensu em Ciência Jurídica da UNIVALI, Itajaí, v.14, n.2, $2^{\circ}$ quadrimestre de 2019. Disponível em: www.univali.br/direitoepolitica - ISSN 1980-7791

\begin{tabular}{|c|c|c|c|}
\hline & & /membership/ & e/membership/ \\
\hline 13 & Ilinois & http://www.ilga.gov/house/ & http://www.ilga.gov/senate/ \\
\hline 14 & Indiana & https://ballotpedia.org/I & Idiana General Assembly \\
\hline 15 & Iowa & $\begin{array}{c}\text { https://www.legis.iowa.gov/legislat } \\
\text { ors/house }\end{array}$ & $\begin{array}{c}\text { https://www.legis.iowa.gov/legislat } \\
\text { ors/senate }\end{array}$ \\
\hline 16 & Kansas & $\frac{\text { http://www.kslegislature.org/li/b20 }}{\underline{1718 / \text { chamber/house/roster/ }}}$ & $\begin{array}{l}\text { http://www.kslegislature.org/li/b20 } \\
17 \text { 18/chamber/senate/roster/ }\end{array}$ \\
\hline 17 & Kentucky & https://ballotpedia.org/Ke & ntucky General Assembly \\
\hline 18 & Louisiana & $\begin{array}{c}\text { http://house.louisiana.gov/H_Reps } \\
\angle H \text { Reps ByDistrict.aspx }\end{array}$ & $\frac{\text { http://senate.la.gov/Senators/bydi }}{\text { strict.asp }}$ \\
\hline 19 & Maine & $\begin{array}{l}\text { http://legislature.maine.gov/house } \\
\text { /house/MemberProfiles/ListAlpha }\end{array}$ & $\frac{\text { http://legislature.maine.gov/senat }}{\text { e/district-listing/9526 }}$ \\
\hline 20 & Maryland & $\begin{array}{l}\text { https://msa.maryland.gov/msa/md } \\
\underline{\text { manual/06hse/html/hseal.html }}\end{array}$ & $\begin{array}{l}\text { https://msa.maryland.gov/msa/md } \\
\text { manual/05sen/html/senal.html }\end{array}$ \\
\hline 21 & $\begin{array}{c}\text { Massachusset } \\
\text { s }\end{array}$ & $\frac{\text { https://malegislature.gov/Legislato }}{\underline{\text { rs/Members/House }}}$ & $\frac{\text { https://malegislature.gov/Legislato }}{\underline{\mathrm{rs} / \text { Members/Senate }}}$ \\
\hline 22 & Michigan & $\frac{\text { http://www.house.mi.gov/MHRPubl }}{\underline{\text { ic/frmRepList.aspx }}}$ & $\begin{array}{c}\text { http://www.senate.michigan.gov/s } \\
\underline{\text { enatorinfo list.html }}\end{array}$ \\
\hline 23 & Minnesota & $\frac{\text { https://www.house.leg.state.mn.us }}{\text { /members/list }}$ & $\begin{array}{c}\text { https://www.senate.mn/members/i } \\
\text { ndex.php?Is=\#header }\end{array}$ \\
\hline 24 & Mississipi & $\frac{\text { http://billstatus.Is.state.ms.us/me }}{\text { mbers/h_roster.pdf }}$ & $\frac{\text { http://billstatus.Is.state.ms.us/me }}{\text { mbers/s_roster.pdf }}$ \\
\hline 25 & Missouri & $\begin{array}{c}\text { https://ballotpedia.org/Missouri_Ho } \\
\text { use of Representatives }\end{array}$ & $\begin{array}{c}\text { https://www.senate.mo.gov/2018- } \\
\text { senator-listing-2/ }\end{array}$ \\
\hline 26 & Montana & https://leg.mt.gov/house/ & https://leg.mt.gov/s \\
\hline 27 & Nebraska* & \multicolumn{2}{|c|}{ https://ballotpedia.org/Nebraska_State_Senate_(Unicameral) } \\
\hline 28 & Nevada & $\begin{array}{c}\text { https://www.leg.state.nv.us/App/L } \\
\text { egislator/A/Assembly/ }\end{array}$ & $\begin{array}{c}\text { https://www.leg.state.nv.us/App/L } \\
\text { egislator/A/Senate/ }\end{array}$ \\
\hline 29 & $\begin{array}{c}\text { New } \\
\text { Hampshire }\end{array}$ & $\begin{array}{l}\text { https://ballotpedia.org/New_Hamp } \\
\text { shire House of Representatives }\end{array}$ & $\begin{array}{c}\text { http://gencourt.state.nh.us/Senate } \\
\text { /members/senate roster.aspx }\end{array}$ \\
\hline 30 & New Jersey & \multicolumn{2}{|c|}{ https://www.njleg.state.nj.us/members/roster.asp } \\
\hline 31 & New Mexico & $\begin{array}{c}\text { https://www.nmlegis.gov/Members } \\
\text { LLegislator List?T }=\mathrm{R}\end{array}$ & $\frac{\text { https://www.nmlegis.gov/Members }}{\text { LLegislator List?T=S }}$ \\
\hline
\end{tabular}


TODESCHINI, Guilherme dos Santos. Redução do Parlamento brasileiro com inspiração no modelo dos Estados Unidos: a inconsistência objetiva do argumento em trânsito no Congresso Nacional brasileiro. Revista Eletrônica Direito e Política, Programa de Pós-Graduação Stricto Sensu em Ciência Jurídica da UNIVALI, Itajaí, v.14, n.2, $2^{\circ}$ quadrimestre de 2019. Disponível em: www.univali.br/direitoepolitica - ISSN 1980-7791

\begin{tabular}{|c|c|c|c|}
\hline 32 & New York & https://nyassembly.gov/mem/ & $\frac{\text { https://www.nysenate.gov/senator }}{\underline{\text { s-committees }}}$ \\
\hline 33 & $\begin{array}{l}\text { North } \\
\text { Carolina }\end{array}$ & $\frac{\frac{\text { https://www.ncleg.net/gascripts/m }}{\text { embers/memberList.pl?sChamber }=}}{\text { House }}$ & $\begin{array}{l}\frac{\text { https://www.ncleg.net/gascripts/m }}{\text { embers/memberList.pl?sChamber }=} \\
\text { senate }\end{array}$ \\
\hline 34 & North Dakota & $\frac{\text { https://www.legis.nd.gov/assembly }}{\not 66-2019 / \text { members/house }}$ & $\frac{\text { https://www.legis.nd.gov/assembly }}{\not 66-2019 / \text { members/senate }}$ \\
\hline 35 & Ohio & \multicolumn{2}{|c|}{ https://www.legislature.ohio.gov/legislators/legislator-directory } \\
\hline 36 & Oklahoma & $\begin{array}{c}\text { https://www.okhouse.gov/Member } \\
\text { s/Default.aspx }\end{array}$ & $\frac{\text { http://www.oksenate.gov/Senators }}{\text { /Default.aspx?selectedtab }=0}$ \\
\hline 37 & Oregon & \multicolumn{2}{|c|}{ https://ballotpedia.org/Oregon State Legislature } \\
\hline 38 & Pennsylvania & $\begin{array}{l}\frac{\text { https://www.legis.state.pa.us/cfdo }}{\text { cs/legis/home/member informatio }} \\
\frac{\text { n/mbrList.cfm?body=H\&sort=distri }}{\underline{\text { ct }}}\end{array}$ & $\begin{array}{l}\frac{\text { https://www.legis.state.pa.us/cfdo }}{\text { cs/legis/home/member informatio }} \\
\frac{\text { n/mbrList.cfm?body=S\&sort=distri }}{\underline{\text { ct }}}\end{array}$ \\
\hline 39 & Rhode Island & $\frac{\text { http://www.rilin.state.ri.us/represe }}{\text { ntatives/default.aspx }}$ & $\frac{\text { http://www.rilin.state.ri.us/senator }}{\text { s/default.aspx }}$ \\
\hline 40 & $\begin{array}{l}\text { South } \\
\text { Carolina }\end{array}$ & https://ballotpedia. & Carolina St \\
\hline 41 & South Dakota & $\frac{\text { http://sdlegislature.gov/Legislators }}{\text { Ldefault.aspx?Session=2019\#divH }}$ & $\begin{array}{l}\frac{\text { http://sdlegislature.gov/Legislators }}{\text { /default.aspx?Session=2019\#divSe }} \\
\text { nate }\end{array}$ \\
\hline 42 & Tennessee & $\frac{\text { http://www.capitol.tn.gov/house/m }}{\text { embers/ }}$ & $\frac{\text { http://www.capitol.tn.gov/senate/ }}{\text { members/ }}$ \\
\hline 43 & Texas & $\begin{array}{c}\text { https://capitol.texas.gov/Members/ } \\
\text { Members.aspx?Chamber }=\mathrm{H}\end{array}$ & $\frac{\text { https://capitol.texas.gov/Members/ }}{\text { Members.aspx?Chamber }=\mathrm{S}}$ \\
\hline 44 & Utah & $\frac{\text { https://house.utah.gov/house- }}{\text { members/ }}$ & $\frac{\text { https://ballotpedia.org/Utah State }}{\text { Senate }}$ \\
\hline 45 & Vermont & $\frac{\text { https://legislature.vermont.gov/pe }}{\text { ople/all/2018.1/House }}$ & $\frac{\text { https://legislature.vermont.gov/pe }}{\text { ople/all/2018.1/Senate }}$ \\
\hline 46 & Virginia & $\begin{array}{l}\text { https://virginiageneralassembly.go } \\
\text { v/house/members/members.php }\end{array}$ & $\begin{array}{c}\text { https://apps.senate.virginia.gov/Se } \\
\text { nator/index.php }\end{array}$ \\
\hline 47 & Washington & http://leg.wa.gov/House/Pages/Me & http://leg.wa.gov/Senate/Senators \\
\hline
\end{tabular}


TODESCHINI, Guilherme dos Santos. Redução do Parlamento brasileiro com inspiração no modelo dos Estados Unidos: a inconsistência objetiva do argumento em trânsito no Congresso Nacional brasileiro. Revista Eletrônica Direito e Política, Programa de Pós-Graduação Stricto Sensu em Ciência Jurídica da UNIVALI, Itajaí, v.14, n.2, $2^{\circ}$ quadrimestre de 2019. Disponível em: www.univali.br/direitoepolitica - ISSN 1980-7791

\begin{tabular}{|l|c|c|c|} 
& & mbersByDistrict.aspx & /Pages/default.aspx \\
\hline 48 & West Virginia & $\frac{\text { http://www.wvlegislature.gov/Hous }}{\text { e/roster.cfm }}$ & $\frac{\text { http://www.wvlegislature.gov/Sena }}{\underline{\text { te1/roster.cfm }}}$ \\
\hline 49 & Winsconsin & $\frac{\underline{\text { https://docs.legis.wisconsin.gov/20 }}}{\underline{17 / \text { legislators/assembly }}}$ & $\underline{\text { https://docs.legis.wisconsin.gov/20 }}$ \\
\hline 50 & Wyoming & $\frac{\text { https://www.wyoleg.gov/Legislator }}{\underline{\text { s/2018/H }}}$ & $\underline{\text { https://www.wyoleg.gov/Legislator }}$ \\
\hline * Parlamento estadual unicameral. & $\underline{\text { s/2018/S }}$ \\
\hline
\end{tabular}

RECEBIDO EM: 27/02/2019

APROVADO EM: 15/04/2019 